\title{
HOME RANGE AND REPRODUCTION OF RODENTS IN MAYNUGUS IRRIGATION FIELD, NORTHERN ETHIOPIA
}

\author{
Workneh Gebresilassie, Afework Bekele*, Gurja Belay and M. Balakrishnan \\ Department of Biology, Faculty of Science, Addis Ababa University, PO Box 1176 \\ Addis Ababa, Ethiopia. E-mail: afeworkbekele@hotmail.com
}

\begin{abstract}
Movement pattern, home range and reproduction of rodent pests were studied in agricultural and moorland habitats in Maynugus, Tigray Region of northern Ethiopia. Trapping was carried out during different phases of agriculture. Eighty-five percent of the resident individuals of both Mastomys erythroleucus and Arvicanthis dembeensis was recorded on grid 1, the most nutritious among the four grids studied. Non-residents were also more in this grid. M. erythroleucus had larger home range than that of $A$. dembeensis. Reproductive males and females of both species had larger home ranges than non-reproductive groups. On grid 1, smaller and denser home ranges were observed than on other grids. The largest home range overlap was observed on grid 1 during the reproductive phase of the crops. A bimodal peak of breeding of rodents was observed in association with the rain-fed and irrigation-fed cultivation periods. Maximum number of embryos was recorded during the end of the main rainy season and during the beginning of the dry season. M. erythroleucus accounted for the highest number of embryos and for the highest percentage of recruitment. The highest recruitment was during the post-harvest season. Based on the peak sexual status of these pests and the reproductive phase of the cultivated plants, rodent pest control measures in this area should be implemented during mid-August and early January.
\end{abstract}

\section{Key words/phrases: Home range, movement pattern, recruitment, reproduction, rodents}

\section{INTRODUCTION}

Among mammals, rodents form the largest order in terms of species diversity. Reproduction is the most vital source of recruitment that influences the population density of rodents (Leirs, 1995). Rodents are also polyestrous, and the young ones mature early (Taylor and Green, 1976). Reproductive patterns of small mammals follow seasonality in relation to variations in the rainfall, and reach peaks at the end of the rainy season when resources are plenty. Extended breeding pattern is also observed during the period of continuous rainfall (Delany and Monro, 1986; Afework Bekele and Leirs, 1997). Most rodents produce 6-7 young after a gestation period of three weeks.

The major rodent pests in Africa are species of Arvicanthis and Mastomys. Arvicanthis is an African diurnal rodent frequently occurring in grasslands. Mastomys and Mus species are common in many parts of Africa (Happold, 1974; Corti and Fadda, 1996). In Ethiopia, 84 species of rodents are known to occur. These include endemic species such as Stenocephalemys albipes, Arvicanthis blicki and Mastomys awashenisis (Yalden, 1988; Afework
Bekele, 1996; Lavrenchenko et al., 1998). Studies on various aspects of ecology of African rodents have been carried out by Baker (1971), Taylor and Green (1976), Delany and Monro (1986), Yalden (1988), Afework Bekele et al. (1993), Afework Bekele (1996), Corti and Fadda (1996), and Workneh Gebresilassie et al. (2004). However, most of these observations were outside irrigated fields. Population dynamics of small mammals in irrigated fields is unique due to the continuous supply of food. Hence this investigation was carried out in agricultural fields at Maynugus, in northern Ethiopia, to understand the home range and reproductive patterns of rodents, and to suggest rodent control measures.

\section{THE STUDY AREA AND METHODS}

\section{The study area}

The study area is located in Laelaymaychew district, Tigray region, between $14^{\circ} 06^{\prime} 01^{\prime \prime}-14^{\circ} 06^{\prime}$ $44^{\prime \prime} \mathrm{N}$ latitude and $38^{\circ} 39^{\prime} 43^{\prime \prime}-38^{\circ} 39^{\prime} 55^{\prime \prime} \mathrm{E}$ longitude, $1000 \mathrm{~km}$ north of Addis Ababa (Fig. 1). The altitude extended from 2008 to $2083 \mathrm{~m}$.

\footnotetext{
*Author to whom correspondence should be addressed.
} 


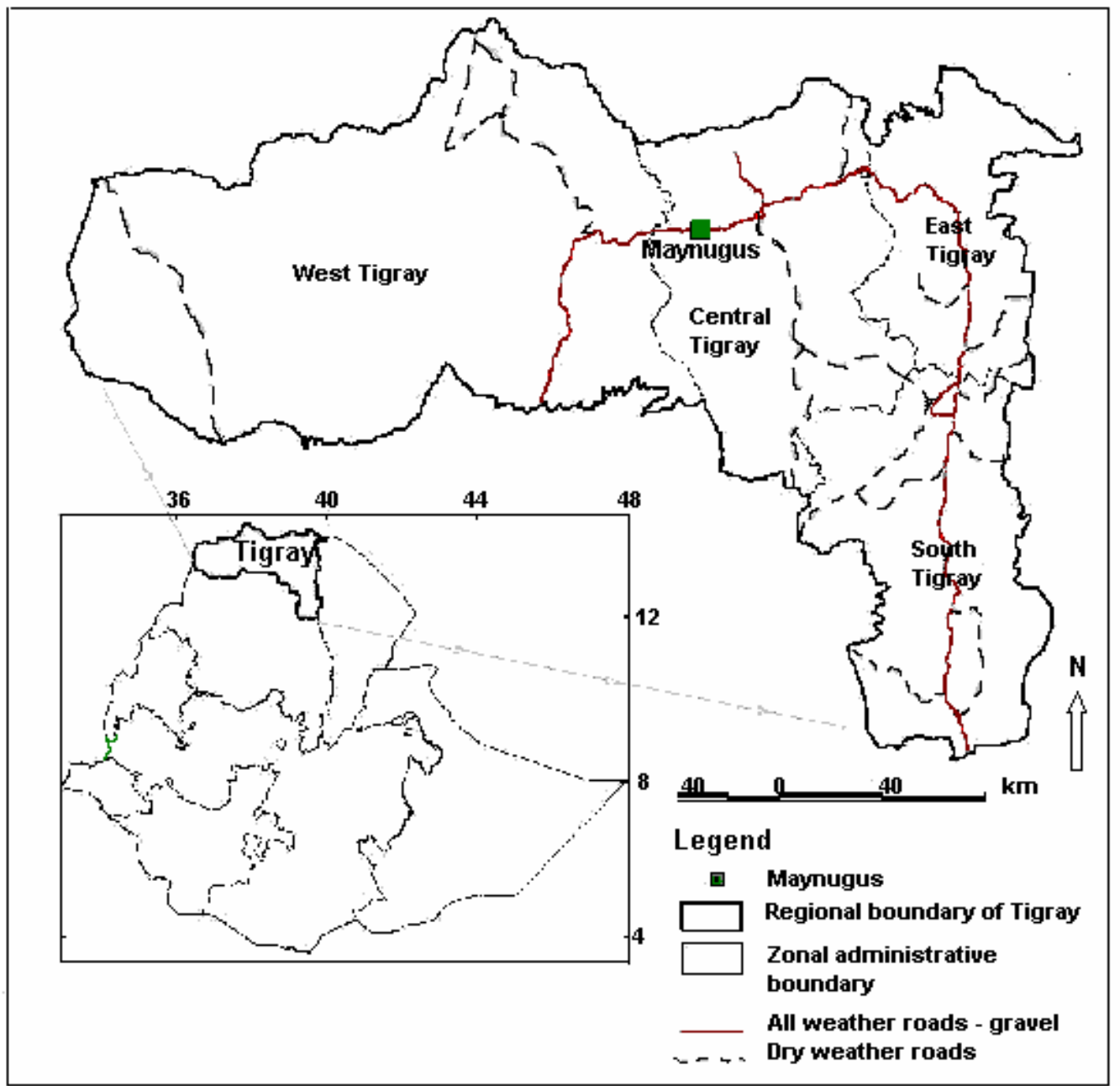

Fig. 1. Map of Tigray region, northern Ethiopia, showing location of the study area.

\section{Methods}

Four grids were laid for live-trapping rodents. Grids 1, 2 and 3 were located in the centre of agricultural fields. Grid 4 comprised a natural vegetation of grassland with Acacia trees, $2 \mathrm{~km}$ away from the other grids. Part of grid 1 was under continuous cultivation due to irrigation. The first trapping session was from the last week of August to mid-September 2001. This was the late rainy season when the crops were in flowering and fruiting stages. The second trapping session was during December 2001, which was the post-harvest phase and commencement of cultivation using irrigation in grid 1 . The third trapping session was from the end of January to the third week of February 2002, the flowering and fruiting phase of the irrigated crops.
Capture-Mark-Recapture (CMR) method was followed using Sherman live traps (Afework Bekele, 1996). Live trapped individuals were marked by toe clipping. In each grid and each trapping period, 49 (7x7) Sherman live traps were set for five consecutive days, at $10 \mathrm{~m}$ apart. The area of each live trap grid was $4900 \mathrm{~m}^{2}(70 \mathrm{~m} \times 70$ $\mathrm{m})$. Removal trapping was carried out by snap trapping in areas around $600 \mathrm{~m}$ away from the live trapping grids. Maize or wheat scraps mixed with peanut butter were used as baits. Traps were checked twice a day, early in the morning and late in the afternoon. The trapped specimens were identified and species, sex, age and sexual conditions were recorded. A Pesola spring balance (100 g) was used to record weight. 
Movement of the individuals was calculated by categorizing the animals into two groups. Residents were those recaptured during all trapping sessions and non-residents were those captured at least once within the trapping period (Leirs, 1995). The size of the home range was estimated by the boundary strip method (Stickel, 1979). Besides weight, sexually mature individuals (adults) were differentiated from immature ones on the basis of sexual conditions (males: scrotal/abdominal testes and females: perforation, pregnancy and lactation). Embryos of snaptrapped pregnant females were recorded. Survival rate from one trapping session to the next was calculated by dividing the number of recaptured individuals over the previous trapping period (Dalby, 1975). Data were analysed by analysis of variance (ANOVA) and Chi-square test (SPSS version 10.1).

\section{RESULTS}

The home ranges of $M$. erythroleucus varied from $743 \mathrm{~m}^{2}$ to $1625 \mathrm{~m}^{2}$. Scrotal males had larger home ranges (mean $747 \mathrm{~m}^{2}$ on grid 1 and $1625 \mathrm{~m}^{2}$ on grid 2) than reproductive females (mean $566 \mathrm{~m}^{2}$ on grid 1 and $967 \mathrm{~m}^{2}$ on grid 2). Non-reproductive males and females had comparatively smaller home ranges, $467 \mathrm{~m}^{2}$ and $425 \mathrm{~m}^{2}$, respectively on grid 1 and $430 \mathrm{~m}^{2}$ and $505 \mathrm{~m}^{2}$, respectively on grid 2 . The home ranges of scrotal males of $A$. dembeensis varied from $400 \mathrm{~m}^{2}$ (on grid 1) to $1300 \mathrm{~m}^{2}$ (on grid 2 ), while those of reproductive females varied from $200 \mathrm{~m}^{2}$ (on grid 1) to $800 \mathrm{~m}^{2}$ (on grid 2). The mean home range of immature males was $367 \mathrm{~m}^{2}$, while that of non-reproductive females was $733 \mathrm{~m}^{2}$. Grid 1 had smaller and denser home ranges than the other grids $(P<0.001)$.

Data on overlap of home ranges of $M$. erythroleucus and A. dembeensis are given in Table 1 .
This was more conspicuous between the home ranges of opposite sexes, when compared to those of the same sex. Males showed more overlap of home ranges $(P<0.001)$, which was greater between males and females than between males themselves $(P<0.001)$. Home range overlap between males and females was also highly significant compared to that between females themselves $(P<0.001)$.

Table 2 gives data on the reproductive status of the trapped rodents. $M$. erythroleucus and $A$. dembeensis have had scrotal males and reproductive females in all trapping sessions. Trapping session 2 recorded more males with abdominal testes in both species $(P<0.001)$. Quiescent females of $M$. erythroleucus and $A$. dembeensis were more during trapping session $2(P$ $<0.01$ ). All females of $A$. dembeensis trapped during trapping sessions 1 and 3 were in active breeding phase. The mean number of embryos in the snaptrapped females of M. erythroleucus during the first, second and the third trapping sessions were 15.3, 9.3 and 4.5 , respectively. The average embryo count was 11.9 for the three trapping sessions. For A. dembeensis, these figures were 7.7, 4.5 and 6.0, respectively, averaging to 7.1 for the three sessions. Both these species had the highest number of embryos during trapping session 1.

Recruitment of M. erythroleucus ranged from 55\% on grid 1 (trapping session 3) to $100 \%$ on other grids and trapping sessions (Table 3 ). Recruitment of A. dembeensis also ranged from 50\% (grid 3) during trapping session 3 to $100 \%$ on other grids and trapping sessions. A. dembeensis was not captured during trapping session 2 on grid 4 . Table 4 shows that the survival rates of $M$. erythroleucus range from 12 to $28 \%$ and those of $A$. dembeensis from 14 to $33 \%$ within 45 days. Adult females of $A$. dembeensis had a survival rate of $16.7 \%$, whereas the young ones had $50 \%$.

Table 1. Home range overlap of rodents in agricultural areas.

\begin{tabular}{|c|c|c|c|c|c|}
\hline \multirow[t]{2}{*}{ Grid } & \multirow{2}{*}{$\begin{array}{l}\text { Trapping } \\
\text { session }\end{array}$} & \multicolumn{3}{|c|}{ Mean area of overlap, $\mathrm{m}^{2}$} & \multirow{2}{*}{$\begin{array}{l}\text { Average area of } \\
\text { overlap, } \mathrm{m}^{2}\end{array}$} \\
\hline & & $\begin{array}{l}\text { Among } \\
\text { males* }\end{array}$ & $\begin{array}{l}\text { Among } \\
\text { females** }\end{array}$ & $\begin{array}{l}\text { Between males } \\
\text { and females** }\end{array}$ & \\
\hline \multirow[t]{3}{*}{$1^{\text {***}}$} & 1 & $480(10)$ & $300(5)$ & $566.7(5)$ & 448.9 \\
\hline & 2 & $300(17)$ & $0(13)$ & $300(30)$ & 200.0 \\
\hline & 3 & 180(10) & $200(10)$ & 200(10) & 193.3 \\
\hline \multirow[t]{3}{*}{2} & 1 & $366.7(6)$ & $250(4)$ & $500(10)$ & 372.0 \\
\hline & 2 & $300(8)$ & $166(11)$ & 200(19) & 222.3 \\
\hline & 3 & - & - & - & - \\
\hline \multirow[t]{3}{*}{3} & 1 & $400(4)$ & 200(3) & $400(7)$ & 333.0 \\
\hline & 2 & - & - & 233(9) & 77.7 \\
\hline & 3 & - & - & - & - \\
\hline \multicolumn{2}{|c|}{ Mean } & 338 & 186 & 344 & 264 \\
\hline \multicolumn{2}{|c|}{ Area of overlap, \% } & 32 & 29 & 41 & 31 \\
\hline
\end{tabular}

${ }^{*} P<0.001$ (between males); ${ }^{* *} P<0.001$ (between females \& between males and females); ${ }^{* * *} P<0.001$ (grid 1 vs other grids). (Figures in parentheses give sample size). 
Table 2. Reproductive status of $M$ erythroleucus (M) and A. dembeensis (A) during different trapping sessions.

\begin{tabular}{|c|c|c|c|c|c|c|c|c|}
\hline \multirow[t]{3}{*}{ Species } & \multirow{3}{*}{$\begin{array}{l}\text { Trapping } \\
\text { session }\end{array}$} & \multicolumn{6}{|c|}{ Individuals of different sexual status } & \multirow{3}{*}{$\begin{array}{l}\text { Reproductive } \\
\text { females }\end{array}$} \\
\hline & & \multicolumn{2}{|c|}{ Male } & \multicolumn{4}{|c|}{$\begin{array}{ll}\text { Female } \\
\end{array}$} & \\
\hline & & Scrotal & Abdominal & Quiescent & Perforate & Pregnant & Lactating & \\
\hline \multirow[t]{3}{*}{ M } & 1 & $27(90)$ & $3(10)$ & $13(50)$ & $9(35)$ & $4(15)$ & 0 & $(50)$ \\
\hline & 2 & $4(31)$ & $9(69)$ & $20(75)$ & 0 & $4(20)$ & $1(5)$ & (25) \\
\hline & 3 & $18(86)$ & $3(14)$ & $3(75)$ & 0 & $4(50)$ & 1(12) & (63) \\
\hline \multirow[t]{3}{*}{ A } & 1 & 11(100) & 0 & 0 & $2(29)$ & $5(71)$ & 0 & (100) \\
\hline & 2 & 1(10) & $9(90)$ & $9(67)$ & 0 & 1(8) & $3(25)$ & (33) \\
\hline & 3 & $3(50)$ & $3(50)$ & 0 & $1(17)$ & $4(67)$ & 1(17) & (100) \\
\hline
\end{tabular}

Note: Figures in parentheses show percentage.

Table 3. Recruitment of new individuals of M. erythroleucus and A. dembeensis during trapping sessions 2 \& 3.

\begin{tabular}{llllllll}
\hline Grid & Trapping & \multicolumn{3}{c}{ M. erythroleucus } & \multicolumn{3}{c}{ A.dembeensis } \\
\cline { 2 - 7 } & session & I & II & III & I & II & III \\
\hline 1 & 2 & 32 & $32(100)$ & $(84.2)$ & 6 & $6(100)$ & $(15.8)$ \\
& 3 & 20 & $11(55)$ & $(68.8)$ & 7 & $5(72)$ & $(31.2)$ \\
2 & 2 & 17 & $17(100)$ & $(89.5)$ & 2 & $2(100)$ & $(10.5)$ \\
& 3 & 5 & $3(60)$ & $(100)$ & - & - & - \\
3 & 2 & 9 & $9(100)$ & $(100)$ & - & - & - \\
& 3 & 6 & $6(100)$ & $(75)$ & 2 & $2(100)$ & $(25)$ \\
4 & 2 & 4 & $4(100)$ & $(30.4)$ & 7 & $7(100)$ & $(69.6)$ \\
& 3 & 2 & $2(100)$ & $(66.7)$ & 2 & $1(50)$ & $(33.3)$ \\
\hline
\end{tabular}

Note: I, umber of individuals captured; II, recruitment; III, \% of total recruits; figures in parentheses give percentages.

Table 4. Survival rate of M. erythroleucus (M) and A. dembeensis (A) from trapping session 2 to trapping session 3 in relation to sex and age.

\begin{tabular}{|c|c|c|c|c|c|c|c|}
\hline \multirow[t]{2}{*}{ Specie } & \multirow[t]{2}{*}{ Sex } & \multicolumn{2}{|c|}{$\begin{array}{c}\text { No. captured in } \\
\text { trapping session } 2\end{array}$} & \multicolumn{2}{|c|}{$\begin{array}{l}\text { No. recaptured in } \\
\text { trapping session } 3\end{array}$} & \multicolumn{2}{|c|}{ Recapture \% } \\
\hline & & Adult & Young & Adult & Young & Adult & Young \\
\hline \multirow[t]{2}{*}{ M } & Male & 8 & 16 & 1 & 2 & 12.5 & 12.5 \\
\hline & Female & 11 & 14 & 3 & 4 & 27.3 & 28.6 \\
\hline \multirow[t]{2}{*}{ A } & Male & 6 & 1 & - & - & - & - \\
\hline & Female & 6 & 2 & 1 & 1 & 16.7 & 50 \\
\hline
\end{tabular}

\section{DISCUSSION}

The pattern of movement in animals changes from time to time based on seasons and on the availability of essential resources such as food and shelter. Seasonal movements of animals are mostly in search of food. It may also be in relation to the breeding patterns. Mammalian breeding activities coincide with season and the availability of food, not only for the breeding partners, but also for the young ones to be borne. During the present investigation, grid 1 had continuous supply of food as a result of rain-fed and irrigation-fed agricultural patterns. Among the residents, about $85 \%$ was in this grid. The negative trapping success coincided with the post-harvest disturbances, when both shelter and food supplies were affected. There was no record of residents during this period. Mortality and emigration occur as a result of such ecological changes in the habitat.

The home range of $M$. erythroleucus was larger than that of $A$. dembeensis. This might be due to the cereal and seed-eating nature of the former and the relative grass-eating nature of the latter. Workneh Gebresilassie et al. (2004) have reported that vegetable fields are frequented by Mastomys whereas Arvicanthis frequents monocot plants. Scrotal males of both species had larger home ranges than the abdominal males. It is necessary for the reproductively active individuals to acquire more food in order to achieve enough energy and succeed in sexual competition. Similarly, Gaulin and Fitzgerald (1988) found scrotal males of meadow voles (Microtus) with larger home range than those of the abdominal ones. Reproductive 
females of both species also showed larger home ranges than the non-reproductive ones. The need for more food is important for reproduction and lactation. Leirs (1995) also found larger home ranges for reproductive females of $M$. natalensis than for non-reproductive ones. The home ranges on grid 1 were comparatively smaller and denser than on other grids. Availability of more food in this grid than on other grids would attract more rodents, leading to competition to occupy areas more suitable for survival. Rodents in areas with fewer resources such as food and cover tend to have larger home ranges, while those on more nutritious grids maintain smaller home range (Dalby, 1975; Taitt, 1981). Habitat deterioration after harvest might have influenced the rodent population to expand their home ranges to overcome scarcity of resources. Home range of deermice (Peromyscus maniculatus) was smaller in areas where food was available in plenty, whereas in areas of poor quality, it was larger (Taitt, 1981).

Both in the Mastomys and the Arvicanthis studied, home range overlap was more between the opposite sexes. This may be an outcome of the sexual affinity of opposite sexes for successful breeding. Braun (1985) also found considerable home range overlap among opposite sexes of giant kangaroo rat (Dipodomys ingens), but none among the same sex. In M. erythroleucus, the mean home range overlap was higher among males than among females. This may indicate that males of $M$. erythroleucus are less aggressive towards each other than the females. In the case of $A$. dembeensis, there was no record of home range overlap among females. The relative grass-loving nature of this species compared to M. erythroleucus might have resulted in the non-sharing of food resource by becoming more territorial. The savanna woodland, in contrast to the agricultural area, had fewer food resources and hence these rodents have to maintain the home range uninterrupted by others to secure enough food. The home range overlap on grid 1, during trapping session 1, would also indicate the positive relationship letween better resource availability and degree of home range overlap. A. dembeensis had home range overlap only on grid 2 where more monocot plants were present. In general, pest rodents occupy areas, where food is plentiful, which is directly related to the fruiting phase of the plant. Reproductively active males maintain larger home ranges than females. During the reproductive phase, animals have to eat more food to acquire more energy. When it comes to rodents, the outcome is severe crop damage. The breeding season of rodents in agricultural areas is related to the fruiting phase of the plants to satisfy their nutritional requirements and to enhance reproductive activities.

Sexually active rodents were recorded in all trapping sessions during the present investigation. Although this is evidence of continuous breeding activity, a bimodal breeding pattern was observed during the present investigation. The peak breeding was after trapping session 1 , around the end of September and during the end of February and the beginning of March. These sessions coincide with the rainy season and the commencement of irrigated cultivation, as observed earlier in irrigation fields in Kano, Sudan (Rabiu and Fisher, 1989) and in Morogoro, Tanzania (Leirs, 1995). The proportion of sexually active males of $M$. erythroleucus was more than females during trapping sessions 1 and 3 . This would enhance the chances of successful mating with estrous females. Sexually active females of $A$. dembeensis were recorded in all trapping sessions. The peak-breeding season of rodents in this irrigation field is associated to the season when food is plenty. During trapping session 2, which coincided with the season of comparative food shortage, quiescent females were more. Such a physiological adaptation would serve as an ideal reproductive strategy for rodents to overcome natural food deficiency.

The number of embryos counted during the present investigation is comparable to the range of 5-19 embryos revealed for $M$. natalensis in the Zambian flood plains (Sheppe, 1972). The highest mean number of embryos for M. erythroleucus and A. dembeensis was during trapping session 1, coinciding the season with nutritious food, as already discussed (Delany and Monro, 1986). Among the juveniles of $M$. erythroleucus captured during trapping session 2, $50 \%$ of the males and $75 \%$ of the females were sexually active when recaptured during trapping session 3. As they were born after the main breeding season, it is assumed that they reached maturity in about 2-3 months (Afework Bekele and Leirs, 1997).

Recruitment was higher during trapping session 2 than during session 3, for both M. erythroleucus and A. dembeensis. This shows the post-breeding effect of trapping session 2 and the pre-breeding effect of trapping session 3. Similarly, Dalby (1975) found higher recruitment of $A$. azarae during breeding season, with lower recruitment during non-breeding season. Grid 1 also accounted for the highest recruitment. M. erythroleucus contributed to the highest percentage of recruitment in all grids and sessions except on grid 4 , during session 2 . On 
grid 4, trapping session 2, higher recruitment of $A$. dembeensis was recorded. This may be related to the greater number of immigrants from agricultural areas as a result of disturbances after harvest. The higher recruitment rates revealed could also be related to the cultivation and harvesting process in the field and to the opportunistic r-strategic population growth of these rodents. In addition to ageing, mortality and emigration may contribute for such a phenomenon (Fernandez et al., 1996).

Rodent attack in agriculture was serious during the fruiting phase of plants (Workneh Gabresilassie et al., 2004). On the basis of reproductive potentiality, it is recommended that rodent pest control measures should be implemented during the flowering season. This is during mid-August for the rain-fed cultivation and the beginning of January for the irrigation-fed agriculture in Maynugus, northern Ethiopia. As there are seasonal changes in the agricultural pattern from area to area or from region to region, information should be gathered for each locality and for each species of rodents for effective control and population management.

\section{ACKNOWLEDGEMENTS}

We are grateful to the International Food Policy Research Institute (IFPRI) and Addis Ababa University for the financial support. We also appreciate the comments of anonymous referees.

\section{REFERENCES}

1. Afework Bekele (1996). Population dynamics of the Ethiopian endemic rodent Praomys albipes in the Menagesha state forest. J. Zool. Lond. 238:1-12.

2. Afework Bekele, Capanna, E., Corti, M., Marcus, F.L. and Schlitter, A.D. (1993). Systematics and geographic variation of Ethiopian Arvicanthis (Rodentia, Muridae). J. Zool. Lond. 230:117-134.

3. Afework Bekele and Leirs, H. (1997). Population ecology of rodents of maize fields and grass-lands in central Ethiopia. Belg. J. Zool. 127:39-48.

4. Baker, H.R. (1971). Nutritional strategies of Myomorph rodents in North American grasslands. J. Mammal. 52:800-805.

5. Braun, E.S. (1985). Home range and activity patterns of the giant kangaroo rat, Dipodomys ingens. J. Mammal. 66:1-12.
6. Corti, M. and Fadda, C. (1996). Systematics of Arvicanthis (Rodentia, Muridae) from the Horn of Africa; a geometric morphometric evolution. Ital. J. Zool. 63:85-192.

7. Dalby, P. (1975). Biology of Pampa rodents in Balcarec area, Argentina. Michigan State Univ. Biol. Series 5:149-272.

8. Delany, J.M. and Monro, H.R. (1986). Population dynamics of Arvicanthis niloticus (Rodentia: Muridae) in Kenya. J. Zool. Lond. 209:85-103.

9. Fernandez, S.A.F., Evans, R.P. and Dunstone, N. (1996). Population dynamics of the wood mouse, Apodemus sylvaticus (Rodentia: Muridae) in a sitka spruce successional mosaic. J. Zool. Lond. 239:717-730.

10. Gaulin, G.J.S. and Fitzgerald, W.R. (1988). Home range size as a predictor of mating systems in Microtus. J. Mammal. 69:311-319.

11. Happold, D.C.D. (1974). The small rodents of the forest savanna farm land association near Ibadan, Nigeria, with observation on reproduction biology. Rev. Zool. Afr. 88:814-838.

12. Lavrenchenko, A.L., Likhnova, P.O., Baskevich, I.M. and Afework Bekele (1998). Systematics and distribution of Mastomys (Muridae, Rodentia) from Ethiopia, with the description of a new species. Ital. J. Mammal. 63:37-51.

13. Leirs, H. (1995). Population Ecology of Mastomys natalensis (Smith, 1834), Implications for Rodent Control in Africa. Agricultural edition, Belgian Administration for Development Cooperation, Brussels.

14. Rabiu, S. and Fisher, M. (1989). The breeding season and diet of Arvicanthis in northern Nigeria. Trop. Zool. 5:375-386.

15. Sheppe, W. (1972). The annual cycle of small mammal population in a Zambian flood plain. $J$. Mammal. 53:445-459.

16. Stickel, F.L. (1979). Population ecology of house mice in unstable habitats. J. Anim. Ecol. 48:871-887.

17. Taitt, J.M. (1981). The effect of extra food on small rodent populations: 1 . deermice (Peromyscus maniculatus). J. Anim. Ecol.50:111-124.

18. Taylor, D.K. and Green, G.M. (1976). The influence of rain fall on diet and reproduction in four African rodent species. J. Zool. Lond. 180:367-389.

19. Workneh Gebresilassie, Afework Bekele, Gurja Belay and Balakrishnan, M. (2004). Microhabitat choice and diet of rodents in Maynugus irrigation field, northern Ethiopia. Afr. J. Ecol. 42:315321.

20. Yalden, W.D. (1988). Small mammals of the Bale Mountains, Ethiopia. Afr. J. Ecol. 26:281-294. 